[2] Examining the prevalence of non-criteria anti-phospholipid antibodies in patients with anti-phospholipid syndrome: a systematic review.Rheumatology 2015;54:2042-2050.

[3] A unique antiphospholipid assay recognizing phospholipid mixture compared with criteria antiphospholipid immunoassays in lupus patients. Lupus 2017;26(6):606-615.

Acknowledgements: We thank all patients and healthy donors whom took part in this study.

Disclosure of Interest: None declared

DOI: 10.1136/annrheumdis-2018-eular.6750

\section{AB0560 1 PATIENTS WITH RHEUMATOID ARTHRITIS AND LUPUS HAVE SIMILAR PREVALENCE OF PERIODONTITIS - A CROSS-SECTIONAL SURVEY}

C. Ciurtin $^{1}$, M. Orlandi ${ }^{2}$, J. Bakshi ${ }^{1}$, J. Guinto ${ }^{1}$, B. Bernstein ${ }^{1}$, F. D’Aiuto ${ }^{1}$

${ }^{1}$ Rheumatology, University College London; ${ }^{2}$ Oral Health, Eastman Dental Hospital, London, UK

Background: Periodontitis (PD) is a chronic inflammatory disease of the gingival tissues triggered by a dysbiotic microflora and causing the loss of soft and hard tissues surrounding the dentition. Over the last two decades, PD has been linked to a systemic inflammatory response and an increased risk of other comorbidities including cardiovascular diseases and diabetes. Numerous observational studies have confirmed an association between PD and rheumatic diseases. Some evidence suggests an association with rheumatoid arthritis (RA) and a beneficial effect of periodontal treatment on RA outcomes. Scarce evidence instead exists on the association between PD and Systemic Lupus Erythematosus (SLE). The main aim of this study was to evaluate the prevalence of PD in RA and SLE.

Methods: We conducted a cross-sectional survey of consecutive eligible outpatients with RA and SLE attending the Rheumatology Department at UCLH. PD diagnosis was estimated administering a validated self-reported questionnaire. Medical histories, cardiometabolic risk factors and assessment of standard biomarkers of inflammation and RA activity were collected as part of the outpatients' visit.

Results: 86 patients affected by RA and 122 by SLE and 5 presenting both diseases were recruited and agreed to complete the questionnaire. PD was detected in 100 patients of the overall survey (47\%). 38 (44\%) patients with RA and 59 (48\%) patients with SLE had prevalent PD. There was no statistically significant difference in the prevalence of PD between the two patients' groups $(p=0.575)$. PD was associated with diagnosis of diabetes $(p=0.023)$, hypertension $(p=0.004)$ and hypercholesterolemia $(p<0.0001)$. Diagnosis of PD was associated with increased levels of C-reactive protein (CRP) $(2.8 \pm 3.3$ vs $4.0 \pm 4.4, p=0.03)$ in the whole population. In RA patients PD was associated with increased CRP (3.2 \pm 3.2 vs $5.2 \pm 4.4, p=0.014)$ and $E S R(9.8 \pm 10.0$ vs $18.3 \pm 16.6, p=0.008)$.

Conclusions: Prevalence of PD is similar in both RA and SLE (approximately $45 \%$ ) and to the UK national estimates (Adult Dental Survey 2009). PD could contribute to an increased inflammatory profile in patients with RA and SLE. Our data highlight the need of assessing oral health needs of patients with rheumatic diseases.

Disclosure of Interest: None declared

DOI: 10.1136/annrheumdis-2018-eular.2532

\section{AB0561 INFECTIONS IN NEWLY DIAGNOSED SPANISH PATIENTS WITH SYSTEMIC LUPUS ERYTHEMATOSUS: DATA FROM THE RELES COHORT}

C. Gonzalez-Echavarri ${ }^{1}$, M. García ${ }^{2}$, G. Espinosa ${ }^{3}$, G. Ruiz-Irastorza ${ }^{1}$, on behalf of Autoimmune Diseases Study Group GEAS. ' Autoimmune Diseases Unit. Internal Medicine Deparment, BioCruces Health Research Institute. Cruces University Hospital; ${ }^{2}$ Autoimmune Diseases Unit. Internal Medicine Department, Cruces University Hospital, BILBAO; ${ }^{3}$ Department of Autoimmune Diseases, Hospital Clinic, Barcelona, Spain

Background: Infections continue to be an important source of morbidity and mortality in systemic lupus erythematosus (SLE). ${ }^{1}$ Susceptibility to infections is thought to be due to a combination of disease related factors and immunosuppression, however differential contributions during disease course has not been yet studied.

Objectives: Using data of patients from the longitudinal inception cohort Registro Español de Lupus Eritematoso Sistémico (RELES), we aimed to analyse how predictors of infection change during the course of the disease. ${ }^{2}$

Methods: Two hundred and eighty-two patients from the RELES cohort were included. Markers of lupus activity, average prednisone doses and use of immunosuppressive drugs were compared between patients with and without infections within the first and second year of disease. For the analysis, drugs given during the first month of follow-up were considered for infections during the first year and medications given during the first year were considered for infections during the second. ${ }^{3}$

Results: Nineteen patients $(6.4 \%)$ had a documented episode of infection during the first year of follow-up and 16 patients $8(5.67 \%)$ during the second. The following variables were associated with infections during the first year: hypocomplementemia at diagnosis $(p=0.01)$, nephritis at diagnosis $(p=0.03)$, SLEDAI score $(p<0.01)$, average dose of prednisone higher than $30 \mathrm{mg} /$ day $(p=0.01)$, methylprednisolone pulses $(p=0.05)$ and mycophenolate use $(p=0.02)$. The independent variables in the final model were hypocomplementemia (OR $4.41,95 \% \mathrm{Cl} 0.96$ 20.2 ) and average dose of prednisone higher than $30 \mathrm{mg} /$ day (OR 6.60, 95\% Cl 1.3-32.4). The following variables were predictors of infections during the second year in the univariate analysis: average dose of prednisone higher than $7.5 \mathrm{mg} /$ day $(p=0.05)$, methylprednisolone pulses $(p=0.07)$, duration of therapy with antimalarials $(p=0.09)$, mycophenolate use $(p=0.01)$ and cyclophosphamide use $(p=0.05)$. The independent variables in the final model were average dose of pre dnisone higher than $7.5 \mathrm{mg} /$ day $(\mathrm{OR} 4.5,95 \% \mathrm{Cl} 0.99-21)$ and duration of therapy with antimalarials as a protective factor (OR $0.99,95 \% \mathrm{Cl} 0.99-1.00$ ).

Conclusions: Patients with high baseline activity are at a higher risk of infection during the first months but intensive lupus therapy, specifically with medium-high doses of prednisone, is the strongest predictor of infectious events. Continued use of antimalarials protects from infections.

\section{REFERENCES:}

[1] Danza A., Ruiz-Irastorza G. Infection risk in systemic lupus erythematosus patients: susceptibility factors and preventive strategies. Lupus. 2013 Oct:22(12):1286-94

[2] Ruiz-Irastorza, et al. Patterns of drug therapy in newly diagnosed Spanish patients with systemic lupus erythematosus. Clin Exp Rheumatol. 2016 May-Jun;34(3):466-72

[3] Ruiz-Irastorza, et al. First month prednisone dose predicts prednisone burden during the following 11 months: an observational study from the RELES cohort. Lupus Sci Med. 2016 Aug 2;3(1)

Disclosure of Interest: None declared

DOI: 10.1136/annrheumdis-2018-eular.6475

\section{$\mathrm{AB} 0562$ \\ EXTRAGLANDULAR MANIFESTATIONS IN PATIENTS WITH PRIMARY SJÖGREN SYNDROME IN A TERTIARY HOSPITAL IN MADRID}

C.M. Pijoan Moratalla, C. Sobrino-Grande, C. De la Puente-Bujidos.

Rheumatology, Hospital Ramón y Cajal, Madrid, Madrid, Spain

Background: Primary Sjögren syndrome (pSS) is a chronic autoinmune disorder characterised by generalised dryness. In a variable percentage of cases (up to $50 \%$ ) patients can present extraglandular disease, which frequently determines the prognosis.

Objectives: To determine the frequency of both glandular and extraglandular disease in patients with SSp seen in a tertiary hospital in Madrid and to compare them with the frequency observed in the large cohorts (SER and EULAR).

Methods: A descriptive, observational cross-sectional study was conducted. We included patients with diagnosis of pSS according to the ACR/EULAR Classification criteria (2016) attended in our Rheumatology Unit from 2012 to 2017. A database was created, including clinical and epidemiological data and a descriptive analysis was carried out comparing the results with those obtained in the SjögrenSER proyect and EULAR group.

Results: 106 patients with pSS were included. $92.5 \%$ were female (98), with a mean age at diagnosis of 45 years (range: $32-58$ ). Frequency of exocrine gland disease is shown in table 1. Dry eye was the most frequent symptom (91\%), with nearly half of them presenting ocular complications. $69.8 \%$ complained of dry mouth and $18.9 \%$ associated complications such as dysphagia and oral candidiasis. 16 patients (15\%) suffered from recurrent parotiditis and $13(12.3 \%)$ from salivary gland enlargement. Glandular disease also included xerosis (25\%), dyspareunia (11.3\%), upper respiratory tract dryness $(12.3 \%)$ and atrophic chronic gastritis (14\%). Frequency of extraglandular disease is shown in table 2 Chronic fatigue was the most frequent symptom, similar to the observed in both cohorts $(50.9 \%)$, followed by arthralgia which was less frequent than in the Spanish cohort (40.6\% vs $34.5 \%)$. 35 patients suffered from inflammatory arthritis and 3 cases associated fibromyalgia, less than the expected $(2.8 \%$ vs $14.6 \%$ and $22 \%-33 \%$ ). Sixteen patients suffered from interstitial lung disease, this being higher than the observed in both cohorts (15.1\% vs $6.64 \%$ and $5 \%$ ). Fewer patients suffered from depression compared with the EULAR group (24.5\% vs $40 \%$ ). Both peripheral neuropathy and renal disease were diagnosed in a percentage of patients similar to the expected $(11.3 \%$ vs $8.92 \%$ y $1.88 \%$ vs $1.83 \%$ respec tively). 7 patients had autoimmune thyroid disease. Finally, 5 patients $(4.7 \%)$ developed lymphoma, 3 of them being MALT lymphoma of the parotid gland 
which is higher than the observed in the Spanish cohort but it is within the EULAR range. The frequency of Raynaud's phenomenon, cutaneous vasculitis, lymphadenopathy, splenomegaly and pericarditis were similar to those observed both in the Spanish national group and EULAR cohort.

Abstract AB0562 - Table 1. Exocrine Gland Disease

\begin{tabular}{|l|c|c|c|}
\hline \multicolumn{1}{|c|}{ EXOCRINE GLAND DISEASE } & $\begin{array}{c}\text { No PATIENTS } \\
\text { AFFETTED }\end{array}$ & PERCENTAGE (\%) & $\begin{array}{c}\text { S SOOGREN-SER } \\
\text { PRECENAGE } \%)\end{array}$ \\
\hline Dry eye & 96 & 91 & 94.51 \\
\hline$-\quad$ Keratoconjunctivitis sicca & 43 & 40.6 & 91.99 \\
\hline Dry mouth & 74 & 69.8 & 94.05 \\
- Recurrent parotiditis & 16 & 15 & 35.24 \\
- Salivary gland enlargement & 13 & 12.3 & 4.35 \\
\hline Xerosis & 27 & 25 & 72.31 \\
\hline Atrophic chronic gastritis & 15 & 14 & 4.81 \\
\hline Upper respiratory tract dryness & 14 & 12.3 & 15.33 \\
\hline Vaginal dryness / dyspareunia & 12 & 11.3 & 48.97 \\
\hline
\end{tabular}

Abstract AB0562 - Table 2. Extraglandular Disease

\begin{tabular}{|c|c|c|c|c|}
\hline $\begin{array}{l}\text { EXTRAGLANDULAR } \\
\text { DISEASE }\end{array}$ & $\begin{array}{l}\text { № PATIENTS } \\
\text { AFFECTED }\end{array}$ & PERCENTAGE (\%) & $\begin{array}{c}\text { SJÖGREN-SER } \\
\text { PERCENTAGE (\%) }\end{array}$ & $\begin{array}{c}\text { EULAR } \\
\text { PERCENTAGE (\%) }\end{array}$ \\
\hline Chronic fatigue & 54 & 50.9 & 63.16 & $50-75$ \\
\hline $\begin{array}{l}\text { Arthralgia } \\
\text { Inflammatory arthritis }\end{array}$ & $\begin{array}{l}43 \\
35\end{array}$ & $\begin{array}{l}40.6 \\
33\end{array}$ & $\begin{array}{r}34.55 \\
2.97 \\
14.65\end{array}$ & $\begin{array}{c}53 \\
15-30 \\
22-33\end{array}$ \\
\hline $\begin{array}{l}\text { Fibromyalgia } \\
\text { Depression }\end{array}$ & 3 & & & $\begin{array}{c}22-33 \\
40\end{array}$ \\
\hline $\begin{array}{l}\text { Depression } \\
\text { Raynaud's phenomenon }\end{array}$ & $\frac{26}{22}$ & $\begin{array}{l}24.5 \\
20.8\end{array}$ & 21.05 & $18-37$ \\
\hline Intersticial lung disease (ILD) & 16 & 15.1 & 6.64 & 5 \\
\hline Cutaneous vasculitis & 15 & 142 & 9.15 & 10-15 \\
\hline Peripheral neuropathy & 12 & 11.3 & 8.92 & $5-10$ \\
\hline Lymphoma & 5 & 4.7 & 1.18 & $5-10$ \\
\hline Renal disease & 2 & 1.8 & 1.83 & $<5$ \\
\hline
\end{tabular}

Conclusions: Extraglandular disease in SS, although less frequent than sicca symptoms, have a special relevance when it comes to patient management. In our study the frequency of both glandular and extraglandular disease was similar to the observed in Sjögren-SER and EULAR groups although there were some differences. Fibromyalgia was less frequent in our group, whereas interstitial lung disease and peripheral neuropathy were more prevalent

Disclosure of Interest: None declared

DOI: 10.1136/annrheumdis-2018-eular.5400

\section{AB0563 METABOLIC SYNDROME PREDICTS NEW DAMAGE IN SYSTEMIC LUPUS ERYTHEMATOSUS PATIENTS}

C. Reátegui-Sokolova ${ }^{1}$, R.V. Gamboa-Cárdenas ${ }^{1}$, M. Medina ${ }^{1}$, F. Zevallos ${ }^{1}$, C. Elera-Fitzcarrald ${ }^{1,2}$, V.R. Pimentel-Quiroz ${ }^{1}$, J.M. Cucho-Venegas ${ }^{1}$, J.L. AlfaroLozano $^{1}$, Z.J. Rodriguez-Bellido ${ }^{1}$, C.A. Pastor-Asurza' ${ }^{1}$, R.A. Perich-Campos ${ }^{1}$, G. S. Alarcón ${ }^{3}$, M.F. Ugarte Gil ${ }^{1,2},{ }^{1}$ Rheumatology, Hospital Guillermo Almenara Irigoyen; ${ }^{2}$ Universidad Científica del Sur, Lima, Peru; ${ }^{3}$ School of Medicine, University of Alabama, Alabama, USA

Background: The metabolic syndrome (MetS) is a complex of interrelated risk factors for the occurrence of cardiovascular disease and diabetes, and it is now both a public health and a clinical problem(. ${ }^{1}$ The MetS has also been reported to be associated with new organ damage, vascular events and mortality in Systemic Lupus Erythematosus (SLE) patients. ${ }^{2}$

Objectives: To determine whether the MetS predicts damage accrual in SLE patients.

Methods: This prospective study was conducted in a cohort of consecutive SLE patients seen since 2012 at one single institution. Patients had a baseline visit and follow-up visits every 6 months. Patients with $\geq 2$ visits were included. Evaluations included interview, medical records review, physical examination and laboratory tests. Damage accrual was ascertained with the SLICC/ACR damage index (SDI) and disease activity with the SLEDAI. The MetS was defined if the patient fulfilled 3 of 5 criteria according to Alberti et al. ${ }^{1}$ Survival univariable and multivariable Cox-regression models were carried out to determine the risk of developing new damage. The multivariable model was adjusted for age at diagnosis, disease duration, socioeconomic status, SLEDAI, baseline SDI, the Charlson Comorbidity Index, baseline use of prednisone (PDN), antimalarials and immunosuppressive drugs.

Results: Two hundred and forty-nine patients were evaluated; 232 were females and 17 males. Their mean (SD) age at diagnosis was 35.8 (13.1) years; nearly all patients were mestizo. Disease duration was $7.4(6.6)$ years. The SLEDAI was 5.2 (4.3) and the SDI 0.9 (1.3). The average daily dose of PDN was $7.3(6.4) \mathrm{mg} / \mathrm{d}$ and the time of exposure to PDN was 6.9 (6.2) years. One hundred and eight patients (43.4\%) had MetS at baseline. During follow-up, 116 (46.6\%) patients accrued at least one new point in the SDI damage index. In multivariable analyses, the presence of MetS was a predictor of development of new damage; with a Hazard Ratio (HR) 1.54 (1.05-2.26); p:<0.029.

Conclusions: The presence of MetS predicts the development of new damage in SLE patients, despite of other well-known risk factors for such occurrence.

\section{REFERENCES :}

[1] Alberti KGMM, Eckel RH, Grundy SM, Zimmet PZ, Cleeman JI, Donato $\mathrm{KA}$, et al. Harmonizing the metabolic syndrome: a joint interim statement of the International Diabetes Federation Task Force on Epidemiology and Prevention; National Heart, Lung, and Blood Institute; American Hear Association; World Heart Federation; International Atherosclerosis Society and International Association for the Study of Obesity. Circulation [Internet]. 2009 Oct 20 [cited 2018 Jan 27];120(16):1640-5. Available from: http://www.ncbi.nlm.nih.gov/pubmed/19805654

[2] Mok CC, Tse SM, Chan KL, Ho LY. Effect of the metabolic syndrome on organ damage and mortality in patients with systemic lupus erythematosus: a longitudinal analysis. Clin Exp Rheumatol [Internet]. 2017 Oct 18 [cited 2018 Jan 27]; Available from: http://www.ncbi.nlm.nih.gov/pubmed/ 29148424

Disclosure of Interest: None declared

DOI: 10.1136/annrheumdis-2018-eular.6106

\section{AB0564 DRY SYNDROME IN RA PATIENTS. COMPARISON WITH SJÖGREN'S SYNDROME PATIENTS}

D. Peiteado ${ }^{1}$, G. Bonilla ${ }^{1}$, R. Montejano ${ }^{2}$, A. Boto ${ }^{2}$, A. Del Hierro ${ }^{2}$ I. Monjo ${ }^{1}$, C. Plasencia ${ }^{1}$, A. Balsa ${ }^{1} .{ }^{1}$ Rheumatology, ${ }^{2}$ Ophthalmology, Hospital Universitario la Paz, Madrid, Spain

Objectives: The aim of the study is to analyse the clinical characteristics of Rheu matoid Arthritis (RA) patients and dry syndrome, and to compare with primary Sjögren's syndrome (PSS) patients.

Methods: Patients with RA and dry syndrome derived from Rheumatology Clinic to Cornea Unit were evaluated. According to symptoms and ophthalmological examination, patients were classified as high or low probability of Sjögren Syndrome (SS). Clinical and laboratory assessments included sex, age and smoking habit, DAS28, erythrocyte sedimentation rate (ESR), C-reactive protein (CRP) rheumatoid factor (RF), anti-citrullinated peptide antibodies (ACPA), antinuclear antibodies (ANA), anti Ro, anti La and presence of other extraarticular symptoms. In addition, the ophthalmological examination data (Ocular Staining Score [OSS] and Schirmer test), salivary gland scintigraphy (SGS) and salivary gland biopsy (biopsy) were analysed. The percentage of patients who would be classified according to the criteria of the Revised American-European Consensus Group (AECG) 2002, NIH-funded Sjögren's International Collaborative Clinical Alliance (SICCA) 2012 criteria and ACR/EULAR 2016 criteria is evaluated. RA patients with high probability of SS are compared with SSP patients. Statistics analysis was made by mean $\pm S D$, and comparison was made by t- Student test (quantitative parameters) and non parametric test (qualitative) $(\mathrm{p}<0.05)$.

Results: 24 RA with dry syndrome were included. $71 \%$ were women and the mean age was $64 \pm 14$ years. The disease duration was $17 \pm 12$ years. All patients had ocular manifestations, $2 / 3$ oral manifestations, and $17 \%$ other extra-articular manifestations. According to DAS28, 33\% of the patients were in clinical remis sion, $33 \%$ in high activity, and the others in low-moderate activity. 17 patients (71\%), 19 (86\%) and 5 (21\%) were positive (+) for RF, ACPA and ANA, respectively. One patient had Anti Ro +and another anti La +. The mean OSS was 4.2 $( \pm 3.1)$ and the average of Schirmer was $10( \pm 11)$. In relation to other tests: 7 patients had a biopsy performed ( 2 positive [29\%]), 5 patients had GGS ( 2 positive [40\%]).

17 of the 24 RA patients (71\%) were considered "high probability Sjögren's Syndrome" (SS and AR). These patients were compared with the PSS group (see table 1), showing differences in immunological parameters, sex, age and in the\% that fulfilled the classification criteria. No significant differences were found in the ophthalmological examinations or the acute phase reactants.

Abstract AB0564 - Table 1

\begin{tabular}{|c|c|c|}
\hline & SS and RA (n 17) & PSS (n 16) \\
\hline OSS (mean $\pm s d)$ & $6 \pm 2$ & $6.4 \pm 2.6$ \\
\hline SCHIRMER (mean \pm sd) & $6.8 \pm 8.3$ & $4 \pm 4$ \\
\hline ANA & $4(23 \%)$ & $16(100 \%)^{\star *}$ \\
\hline Anti RO/ANTI LA & $1(6 \%) / 1(6 \%)$ & $15(94 \%) / 13(81 \%)^{* *}$ \\
\hline ACPA (media $\pm D S)$ & $667 \pm 866$ & $0.1 \pm 0.3^{* *}$ \\
\hline Gender $(\delta / q)$ & $6 / 11$ & $0 / 16^{*}$ \\
\hline AECG 2002 criteria & $4(23 \%)$ & $15(94 \%)$ ** \\
\hline $\begin{array}{l}\text { N (\%) } \\
\text { ACR } 2012 \text { criteria }\end{array}$ & $2(12 \%)$ & $15(94 \%)$ ** \\
\hline $\begin{array}{l}\text { N (\%) } \\
\text { ACR/EULAR } 2016 \text { criteria } \\
N(\%)\end{array}$ & $3(18 \%)$ & $16(100 \%)$ ** \\
\hline Age & $66.7 \pm 11.6$ & $56 \pm 17.2^{*}$ \\
\hline
\end{tabular}

${ }^{*} p<0.05 ;{ }^{* *} p<0.01$ 